\title{
LEGISPRUDENCIA COMO UNA NUEVA TEORÍA DE LA LEGISLACIÓN
}

Luc J. Wintgens

Academia Europea de Teoría Legal (Bruselas)

\section{Preliminar}

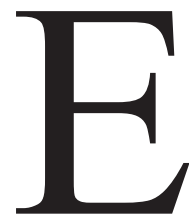

n este artículo sostendré que la separación entre el derecho y la política que ha predominado hasta hace poco en el pensamiento legal, requiere alguna reconsideración. A causa de esta separación, la creación del derecho por medio de la legislación no ha sido considerada como un tema merecedor de atención por la teoría legal. ${ }^{1}$ La legislación pertenece al terreno del enfoque político llevado a cabo por científicos políticos de diferentes tipos. Por su parte, se reconoce que el derecho tiene como origen la política, aunque adquiere vida propia una vez que se separa de ésta. El derecho tiene su propio método de estudio, denominado dogmática jurídica o, más ampliamente, teoría jurídica de diferentes tipos. La forma como el derecho es creado a través del proceso de legislación no aparece en la pantalla del teórico jurídico. La pregunta acerca de por qué es esto así y una crítica a esta posición es el tema de este artículo.

La tesis central es que el derecho es separado de la política por una razón política. ${ }^{2}$ La separación opera en terrenos epistemológicos lo que contribuye a ocultar la elección que realiza la política. Como resultado, el dominio de valores tanto moral y político es estructurado en una base "neutral" que impide la elaboración de una teoría racional de la legislación. ${ }^{3}$

${ }^{1}$ Al respecto, véase J. Waldron, The Dignity of Legislation, Cambridge, Cambridge University Press, 1999, 2 ss.

${ }^{2}$ Cf. la tesis adelantada por Lon Fuller en L. L. Fuller, The Law in Quest of Itself, Chicago, Foundation Press, 1978, 28, 75; and G Postema, Bentham and the Common Law Tradition, Oxford, Oxford University Press, 1986, 328 ss, en el tipo de positivismo por razones normativas.

${ }^{3}$ En este respecto, discrepo con Jeremy Waldron, quien reclama que: "We paint legislation up in these lurid shades [deal-making, horse-trading, log-rolling, etc.] in order to lend credibility to the idea of judicial review (...)." (J. Waldron, The Dignity of Legislation, 2). Aunque esta tesis pueda ser correcta para el sistema jurídico americano donde existe la judicial review, 


\section{EI Contrato Social y los tres ejes de la Filosofía Moderna}

La elaboración de la legisprudencia como una teoría racional de la legislación se inicia con una reflexión sobre la organización del espacio político desde la Modernidad. El modelo básico de esta organización es el contrato social. Este contrato es un acto de voluntad de los sujetos. A su conclusión, surge un soberano. Desde el momento de su surgimiento, el soberano tiene el poder para decidir acerca de asuntos de razón práctica. Él decide acerca el qué y el cómo de la acción humana.

La articulación del soberano es presupuesta por una reflexión sobre la libertad. Esta reflexión articula los tres principales ejes del proyecto filosófico moderno, es decir, la epistemologización de la filosofía, el eje político resultante de la construcción del Estado y el eje moral principalmente concentrado en la libertad del individuo.

La premisa básica que tanto Hobbes como Rousseau adoptan es la libertad ilimitada.

Para Hobbes, cualquiera puede actuar en libertad en el ius naturale. Ello incluye un derecho de todos a todo. Los derechos de la naturaleza imponen algunos deberes que, sin embargo, son impracticables en el estado de naturaleza. Esto debido a su epistemología nominalista. Acorde con esta epistemología, los conceptos carecen de valor ontológico. Su definición depende de los sujetos. Debido a que es más probable que todos definan estos conceptos siguiendo sus propios prejuicios, los derechos de la naturaleza son impracticables. En resumen, ellos existen aunque son semánticamente vacíos. Sólo un soberano puede definir su contenido en forma vinculante. A menos que sea este el caso, hay una guerra de todos contra todos.

Un pensamiento similar, aunque ligeramente diferente en sus tesis, se encuentra en Rousseau. Acorde con él, el hombre nace libre pero encadenado por todas partes. La de Rousseau es, principalmente, una teoría económica. Para Rousseau, así como para Hobbes, la conclusión de un contrato es una condición necesaria para protegerse de los peligros de esta guerra.

De ahí se sigue que la libertad es principalmente considerada un tema político. La libertad llega a su realización en el espacio político como un resultado de la voluntad de sujetos individuales.

La libertad de éstos como una cuestión moral es únicamente un asunto secundario. La libertad individual y la posibilidad de los sujetos de interactuar en sus propias ideas en el espacio social son superadas por la variante

aunque largamente criticada, no es incorrecta para los sistemas de derecho civil donde no existe la judicial review sino desde hace poco (e.g. en Bélgica) o no existe del todo (e.g. en los Países Bajos). Desde esta perspectiva, las razones para la falta de interés en, o la ausencia de una teoría de la legislación debe ser buscado en otra parte. 
política de la libertad o la libertad acorde con el derecho. La organización del espacio político es sobrepuesta en una forma de espacio social autorregulado en el que ni Hobbes ni Rousseau creían. Mientras el soberano no regule un aspecto, los sujetos pueden actuar como ellos quieran. El soberano de todas formas puede intervenir cuando lo juzgue apropiado, en vista de la irrevocabilidad de su posición.

Aparte de los componentes políticos y morales de la libertad, la teoría del contrato social, aparentemente, es principalmente teñida por el tercer eje, que es la perspectiva epistemológica.

En comparación con Descartes, tanto Hobbes como Rousseau enfrentan a la libertad como un problema. Mientras que Descartes es de la opinión de que la moral puede revelarse como un sistema racional, Hobbes y Rousseau consideran que ello no es posible. Ellos se encuentran en un camino más realista que su precursor. Apoyan, sin embargo, sus percepciones básicas que derivan en una epistemología de filosofía en general y de filosofía práctica en particular.

La verdad filosófica para Descartes viene a asegurar la certeza de éste. Las ideas que tienen la misma claridad y distinción que el cogito pueden ser lógicamente concatenadas a este último y así unas a otras. Sobre esto, la realidad puede revelarse en un camino racional. Por el contrario, lo que no es capaz de pruebas lógicas o empíricas, por consiguiente, no es racional.

Fructífero como esto pudo haber resultado para el pensamiento científico reduce fuertemente, sin embargo, el radio de acción de la razón práctica. Valores o metas y fines de la acción no son susceptibles de pruebas lógicas o empíricas; por lo tanto, no son racionales. Estos efectos se han sentido por unos tres siglos y persisten durante todo el programa del positivismo lógico.

El modelo del contrato social, como Hobbes y Rousseau lo conciben, pretende ser la solución al problema de la integración política como se sigue del individualismo. Ellos lo hicieron además aplicando y extendiendo el método cartesiano de transformación del pensamiento en conocimiento. Es decir, se entregan a un específico ejercicio de filosofía epistemológica.

Para empezar, el contrato social es una idea verdadera. Haciendo uso de sus capacidades racionales, el sujeto no puede sino concluir que aceptar el contrato es preferible a mantenerse en el estado de naturaleza. En lenguaje raziano, la razón para entrar al contrato es una razón excluyente. Mientras Hobbes puede ser leído para sostener una cierta versión utilitaria del racionalismo, la de Rousseau, más obviamente, es de una calidad más refinada. Es la razón en sí misma que revela e induce a adherirse a los verdaderos principios del derecho público, como denomina al contrato social.

Ambas variantes del contrato resultan, sin embargo, en lo mismo: las reglas del soberano son moralmente verdaderas. Lo son en la variante ho- 
bbesiana porque las reglas del soberano son realizaciones de los derechos de la naturaleza. Éstas son mandatos de Dios, son la única moral verdadera. Ellas también son verdaderas en la versión de Rousseau pues ningún derecho, porque es un derecho, puede ser injusto.

La lógica de ambas variantes del contrato social es casi ineludible. De la verdad de la premisa, cual es el contrato social, uno puede lógicamente concluir la verdad de las proposiciones basadas en ella, es decir, los derechos.

\section{Legalismo}

Del diagnóstico precedente, podemos proceder a una articulación de la característica principal del patrón del pensamiento jurídico que ha dominado desde el siglo XVII hasta la mitad del siglo pasado. Es comúnmente signado como "legalismo". El legalismo, como podemos leer de Judith Shklar, toma el comportamiento normativo como una materia de seguimiento de reglas. Zenon Bankowski ha añadido a esto que no importa de dónde vienen estas reglas. Es decir, el Derecho está "justo ahí".

Esta adición trae a relucir, además, una característica del legalismo compartida por el positivismo y el iusnaturalismo. Ambos sostienen que el derecho representa la realidad. Esto es obvio para el iusnaturalismo. El contenido del derecho es dictado por una norma sustancial trascendente que es reproducida por el derecho del soberano. Este representacionalismo es menos obvio en el positivismo. El derecho como mandato de un soberano es una decisión de éste. Es, sin embargo, verdadero según lo exigían tanto Hobbes como Rousseau porque está basado en el contrato social. Es verdadero $\mathrm{y}$, en consecuencia, las reglas basadas en él deberán también ser verdaderas. Es una consecuencia de su versión epistemologizada de la filosofía.

El representacionalismo, como la premisa metafísica básica de sus teorías, es complementado con otros cuatro aspectos que identifican al legalismo. Primero, si la construcción del derecho resulta en proposiciones normativas verdaderas, éstas deberán ser intemporales. Si no lo fueran, difícilmente podrían ser tomadas como verdaderas puesto que la verdad es eterna.

En segundo lugar, puesto que los derechos son verdaderos no hay discusión acerca de su contenido. Esto supone que el natural conflicto de valores, metas y fines es ocultado. Cualquier regla es verdadera, lo que significa que el valor, meta o fin es moralmente correcto. Desde este punto de vista, los derechos son considerados instrumentos para su realización sin que ninguno tenga que ser elegido. Esta característica del legalismo puede ser llamada instrumentalismo oculto.

En tercer lugar, sobre la conclusión del contrato social cualquier proposición normativa del soberano ipso facto importa más que cualquier otra proposición que pretenda tener valor normativo. Las ideas morales persona- 
les de los sujetos sobre lo que es correcto o incorrecto son definitivamente apartadas de la pantalla normativa. Es el derecho del Estado el que prescribe qué es lo correcto y lo incorrecto. Este aspecto del legalismo puede ser calificado como estatismo.

En cuarto y último lugar, el estudio del derecho es confinado al estudio de las proposiciones verdaderas. En cuanto a su método, el estudio del derecho se lleva a cabo en forma idéntica a las ciencias naturales. El método científico de descripción y explicación de un objeto encontrado "fuera" se aplica igualmente tanto al derecho como a la naturaleza. Las proposiciones resultantes de la ciencia del derecho pueden operar como una fuente complementaria del derecho. Esta conclusión es el resultado lógico de la verdad de las premisas - el derecho- y la singularidad del método de la ciencia. Desde entonces, el sistema legal es un conjunto cerrado de proposiciones lógicamente conectadas.

El legalismo, entonces, consiste en una conjugación de estas cinco características -representacionalismo, intemporalidad, instrumentalismo oculto, estatismo y un modo científico de estudio del derecho-. Propongo referirme a esta forma de legalismo como "legalismo fuerte" y lo matizaré luego.

\section{Legalismo fuerte y el modelo de poder del Contrato Social}

La breve articulación del legalismo precedente arroja algunas luces a la teoría de la legislación. El legalismo, principalmente, intenta excluir cualquier forma de teorizar en la legislación. La legislación es una materia política. La política es una materia de opción. Las opciones son discutibles, por lo que una teoría que las tome como objeto de conocimiento es condenada al fracaso desde un inicio. Entonces el legalismo soluciona este problema mediante su epistemologizáción y transformación de la razón práctica en una rama de la razón teórica. El qué debería hacerse es confinado al conocimiento de las reglas que contienen derechos y deberes. El seguimiento de las reglas es una materia del conocimiento; su cumplimiento es una materia de aplicación.

Por consiguiente, la posición central del juez como el principal actor dentro del sistema legal y la posterior reducción de la jurisprudencia a la teoría de la aplicación de reglas es evidente. El legislador opera tras la escena del sistema legal. Su rol es confinado a la toma de decisiones políticas. Los verdaderos principios de derecho público, como Rousseau calificó al contrato social, tienen que ver con el establecimiento de instituciones, y no con el contenido de las decisiones que resultan de ellas.

Esta es una consecuencia de la soberanía. El legislador es un actor soberano dentro del espacio político. Él no puede estar limitado por las reglas, al menos no en el sentido en que lo está un juez. Si lo estuviera, no sería un 
soberano. En este punto de vista, la Constitución es un programa político que dirige la legislación. No es un conjunto de reglas vinculantes para el legislador. En consecuencia, el legislador no es considerado un actor legal. Únicamente es un actor político. Así, la legislación es una cuestión de la política. Al separarse el derecho de su origen político, la elaboración de la ley no es una materia de teoría legal.

En las siguientes páginas, cuestionaré esta visión. La discusión de este artículo tiene como objetivo articular la posición del legislador como un actor legal. Lo haré en tres etapas. En el resto de este parágrafo, exploraré brevemente el significado de la libertad. El parágrafo siguiente es dedicado a la articulación de los contornos de una versión alternativa al contrato social. En el parágrafo final, identificaré cuatro principios de la legisprudecia, que permitan la elaboración racional de la legislación.

Este bosquejo tentativo no tiene la pretensión de ser completo. Solamente contiene contornos rudimentarios de la legisprudencia como una teoría de la legislación que es elaborada más extensamente en una próxima publicación. ${ }^{4}$

Propongo empezar por el concepto de libertad. En ausencia de cualquier limitación externa, cualquier sujeto es libre de actuar como uno quiera. ${ }^{5}$ Tanto Hobbes como Rousseau toman esto como su punto de partida. Como una cuestión de lógica, el sujeto encara una infinita variedad de posibilidades para concretar el concepto de libertad. El concepto de libertad permite cualquier acción. Paradójicamente, la libertad tiene que ser limitada para que la acción sea posible. Si ninguna opción es seleccionada entre la infinita variedad de posibilidades, ninguna acción tendrá lugar nunca.

Esto viene a decir que la acción, para ser posible, es precedida por una limitación de la libertad. La libertad ilimitada es sólo un concepto; debe ser suplido con la concreción de lo que propongo llamar una "concepción". Es decir, las concepciones son una condición necesaria para la acción.

En ausencia de cualquier limitación externa de la libertad, los sujetos actuarán según sus propias concepciones. Ellos tienen que elegir para las limitaciones de la libertad lo que propongo llamar "concepciones de la libertad". Las concepciones de la libertad son concreciones de la misma y esas concreciones son determinaciones de la infinita variedad de posibilidades. Las concepciones de la libertad son limitaciones de la libertad por el sujeto. Cuando el sujeto actúa en una concreción de libertad que no es suya, actúa

${ }^{4}$ L. J. Wintgens, The Justification of Legislation. Legisprudence as a New Theory of Legislation, pro manuscr., $410 \mathrm{p}$.

${ }^{5}$ Cf. H. L. A. Hart, “Are There Any Natural Rights” en D. Lyons (ed.), Rights 14 (Belmont Wadworth Publ. Comp., 1979), 14-25. 
de acuerdo con una concepción sobre la libertad. Una concepción sobre la libertad puede también ser denominada como una limitación externa de la libertad, puesto que la limitación que es necesaria para la acción es externa al sujeto. Al contrario, una concepción de la libertad puede ser considerada como una limitación interna de la libertad.

Lo que tanto Hobbes como Rousseau ansían demostrar es que la interacción social no puede tener lugar sobre la base de concepciones de la libertad. Esto es más obvio en el caso de Hobbes. Acorde con él, los sujetos no disponen del verdadero significado de las leyes de la naturaleza. Esto debido a su vacío semántico. Una vez que logremos el verdadero significado de las leyes de la naturaleza, la interacción social se deshace de las reglas.

A diferencia de Hobbes, Rosseau sostiene que existe una sociedad antes de que nazca un Estado. Su teoría adopta la posibilidad de la interacción social basada en el significado. Es decir, los sujetos interactúan en un contexto de participación. Es dentro de este contexto de participación que ellos se reconocen como miembros de una sociedad limitada. La existencia de una guerra de todos contra todos es un señal de que ahí hay una sociedad. Es decir, la guerra es una forma de interacción social.

El significado, sin embargo, es diferente de la verdad. La verdad es única mientas que los significados son múltiples. La interacción social basada en significados, es decir, la interacción social desde la perspectiva de un contexto de participación está condenada al fracaso. Ello es así por la maldad natural del hombre tal como se puede ser leído de Hobbes. Acorde con Rousseau, es debido a las relaciones de dependencia resultante del marco económico dentro del espacio social.

Esto puede ser reformulado en la terminología precedente. Los sujetos que actúan en concepciones de libertad no disponen de su "verdadero" significado. Las concepciones de la libertad son de una variedad infinita; el "verdadero" significado de la libertad, por su parte, debe ser único.

Los tres ejes que fueron apuntados precedentemente aparecen en el escenario contractual de la siguiente manera. Las concepciones de la libertad como la base de la acción del sujeto son de una necesidad práctica. Sin concepciones de la libertad no puede haber acción. Esta necesidad práctica incluye al mismo tiempo una prioridad del sujeto. Si no hay limitaciones externas a la libertad, es decir, concepciones sobre la libertad, los sujetos pueden actuar como ellos quieran. Sin embargo, tal como Hobbes y Rousseau lo sostuvieron, la necesidad práctica de concreción de la libertad es reformulada como una prioridad política. Las concreciones de la libertad por el soberano, es decir, las concepciones sobre la libertad, predominan sobre las concepciones de la libertad. Ellos lo hacen así por una razón epistemológica. 
Esta razón es epistemológica en aquello que tiene carácter excluyente. Hobbes y Rousseau presumen que todos los sujetos están dotados con idéntica capacidad racional. Al usar su capacidad racional, todos ellos llegarían a la conclusión de que entrar en el contrato es preferible a permanecer en el estado de naturaleza. Es decir, en esta presunción, la verdad es racionalmente preferida al mero significado.

Luego, la organización política de la libertad, por una razón epistemológica, importa más que la prioridad moral del sujeto de actuar en concepciones de libertad. Desde el "momento" del contrato, los sujetos principalmente actúan en concepciones sobre la libertad. Su consentimiento al contrato incluye un poder al soberano. En este poder, ellos consienten en acatar cualquier limitación externa a la libertad del soberano cualquier fuera su contenido.

El mecanismo del modelo de poder opera en sí mismo, sin embargo, como una concepción de la libertad. Son los sujetos quienes actúan en una concepción de la libertad cuando entran en él. Las concepciones sobre la libertad que resultan de ahí son atribuidas a ellos como si fueran concepciones de la libertad. Es a lo que viene el poder general.

Esto se basa, sin embargo, en una idea equivocada de la libertad. La libertad significa la posibilidad de actuar en concepciones de la libertad en ausencia de cualquier limitación externa, es decir, concepciones sobre la libertad. Hablando más generalmente, la libertad es el punto de partida de la organización del espacio político. Este es el significado de la libertad como principio o principium. Un principium, sin embargo, también significa principio guía como "leitmotiv". Desde esta perspectiva, la libertad no es solo el punto de partida de la organización del espacio político.

Esto tiene, sin embargo, también una dimensión moral que es superada por la dimensión política. Como fuera sostenido anteriormente, esto sucede por una razón epistemológica. La consecuencia de esto es lo siguiente: si la organización política de la libertad pesa más que su dimensión moral, la acción en concepciones sobre la libertad siempre y automáticamente pesa más que las concepciones de la libertad. Esto, sin embargo, afecta el carácter reflexivo del concepto de libertad. El carácter reflexivo de la libertad es lo que lo hace un concepto moral. Como un concepto moral, articula la autonomía moral. La autonomía moral requiere libertad para ser ejercida en libertad. Esto es lo mismo que decir que la actuación en concepciones de la libertad tiene prioridad sobre la actuación en concepciones sobre la libertad.

Esto es lo negado en la teoría del contrato social. El poder pesa más que la libertad en el sentido moral en esas concepciones sobre la libertad, siempre tiene prioridad sobre las concepciones de la libertad. 


\section{Legalismo débil y el modelo de compensación del Contrato Social}

En contra del modelo de poder del contrato social, propongo bosquejar las características de un modelo diferente. Si cualquier limitación de la libertad es, por su sola existencia, legitimada ipso facto, esto da lugar a lo que atestiguamos hoy en día como el crecimiento exponencial de los sistemas legales. Cualquier limitación externa de la libertad que es formalmente legitimada como un dicho del soberano es una regla válida.

Debido a que el poder es general, se supone que el sistema legal como un todo debe tener un propósito general. El poder es dado por una razón -la seguridad de la propia vida en Hobbes o la garantía de igualdad y libertad en Rousseau- y esta razón es el propósito del sistema legal como un todo. Ella, a priori, justifica cualquiera de las futuras limitaciones externas, el contenido de las cuales es todavía desconocido al "momento" del contrato. Por consiguiente, ambos, el poder y el propósito del sistema legal, son generales. En esta caracterización, cualquiera de las limitaciones externas es cubierta por el poder y sirve al propósito del sistema legal. Su número no es limitado por ningún criterio.

El aspecto cuantitativo del orden legal es un problema bien conocido hoy en día. Por más importante que esto sea no será tratado en los alcances de esta contribución. Ésta será limitada a la cualitativa transformación de la libertad sobre la base del contrato social.

Éste es una racional reconstrucción del aristotélico paraíso perdido, es decir, la sociedad política natural. El individualismo metodológico es difícil de conjugar dentro del cuerpo político sin un poco de pegamento racional y conceptual que integre las partes individuales en un todo. La sociedad política natural es sustituida por la sociedad política racional con la ayuda del contrato social.

Como una hipotética reconstrucción, sin embargo, pone en peligro la dimensión moral de la libertad. Si cualquier limitación externa o concepción sobre la libertad puede ser legítimamente sustituida por cualquier limitación interna o concepción de la libertad, se sigue que la concreción de la libertad en el sentido moral puede ser siempre reemplazada por una concreción de la libertad en sentido político.

La razón para concluir el contrato social coincide con la finalidad del Estado o el propósito general del sistema legal. Desde esta perspectiva, puede preguntarse si la libertad en sentido moral puede ser el propósito general del sistema legal.

Si la libertad en el sentido moral es considerada el propósito general o el leitmotiv del sistema legal, tenemos una versión más fina del contrato social. En esta versión, es el derecho el que hace posible a la moral. Esto incluye una diferente caracterización de la relación entre derecho y moral, la cual 
simplemente apunto sin profundizar en ella. Basta decir que en esta caracterización de la relación entre derecho y moral, la moral tiene una prioridad sobre el derecho.

De lo anterior no debe ser concluido que esta prioridad es absoluta. Es una prioridad relativa en que las concepciones sobre la libertad pueden importar más que las concepciones de la libertad. El desafío de la prioridad absoluta de concepciones sobre la libertad refiere a un modelo alternativo del contrato social, que propongo llamar modelo de compensación.

En el modelo de compensación, los sujetos no entregan un poder general al soberano. Por el contrario, el modelo incluye que la libertad sea compensada con todas y cada una de las limitaciones externas. Dicho de otra forma, el modelo de poder contiene una general y, a priori, compensación de la libertad. El modelo de compensación, por el contrario, matiza el carácter de poder del contrato social, en que los sujetos no compensan su capacidad de actuar en concepciones de libertad; ellos solamente compensan una concepción de la libertad.

A diferencia con Hobbes, este modelo de compensación no está basado en una valoración de la naturaleza humana que actúa en impracticables concepciones de la libertad. Es diferente de Rousseau en que no incluye una apreciación general de la sociedad humana que afecta a la interacción social y culmina en guerra.

El modelo de compensación provee los tres ejes del proyecto de la filosofía moderna y los pone en un nuevo escenario.

El eje epistemológico es reformulado de manera que el significado de un concepto no es idéntico a la verdad. Es decir, los conceptos tienen diferentes significados dependiendo del contexto de participación. La negación de la distinción entre la verdad y el significado llega a una negación de la idea de un contexto de participación de todos. La verdad existe independientemente de cualquier contexto aunque no el significado. La igualación de la verdad y el significado o la idea del "significado verdadero" dieron lugar a adoptar una "visión desde ninguna parte" que subyace al representacionalismo propio del proyecto de la filosofía moderna.

El eje político del proyecto tiene como objetivo la institucionalización de la verdad así descubierta o descubrible en principio. El resultado de esto para el eje moral es bastante claro: los sujetos no se suponen capaces de actuar según sus propias comprensiones morales o concepciones de la libertad, debido a su naturaleza (Hobbes) o debido a su vida en sociedad (Rousseau).

La distinción epistemológica entre "concepto" y "concepciones", por su parte, tiene el potencial de encontrar el equilibrio entre el eje político y el moral. Las concreciones de la libertad a modo de concepciones sobre la libertad, automáticamente, entonces, no pesan más que las concepciones 
de la libertad. Si lo fueran, entonces simplemente no hay un equilibrio que encontrar.

Hay, sin embargo, un equilibrio que buscar en el modelo de compensación. Esto es precisamente a lo que viene la compensación. Cualquier regla del soberano es una limitación externa de la libertad. En la libertad como principium, las concreciones políticas y morales del concepto de libertad -es decir, concepciones sobre y concepciones de la libertad- tienen que ser pesadas y balanceadas. ${ }^{6}$

En la libertad como principium, las concepciones de la libertad tienen una prioridad prima facie. Ella puede ser superada por concepciones sobre la libertad con la condición de que estén justificadas como preferibles a las concepciones de la libertad. Esta justificación tiene como objetivo encontrar el equilibrio entre el eje político y moral.

El requisito de justificación, por su parte, expresa la prioridad de la moral sobre las concreciones políticas de la libertad. En adición a esto, la posibilidad de que la concreción moral pueda ser superada por la concreción política de la libertad, muestra que la prioridad es sólo relativa.

\section{Los principios de la Legisprudencia}

En la libertad como principium, cualquier limitación externa de la libertad debe ser justificada. Esto viene a justificar la sustitución de una concepción sobre la libertad por una concepción de la libertad. El deber de justificación es de lo que trata la legisprudencia. La legisprudencia es definida como una teoría racional de la legislación. Esto consiste en una elaboración de la idea de la libertad como principium.

La justificación de la legislación es marcada como un proceso de pesar y balancear la moral y las limitaciones políticas de la libertad. Sobre el carácter racional de la legislación, es requerida una estructura de principios. Con la ayuda de esta estructura, las limitaciones externas pueden ser justificadas. La justificación es parte del proceso de legitimación. Esto no conduce a una limitación externa para ser justificada en última instancia. ${ }^{7}$ Las limitaciones externas nunca son legitimadas como tales. Son sometidas a una legitimación en curso, como será clarificado en las siguientes páginas.

La estructura es conformada por cuatro principios que expondré brevemente y comentaré de aquí en adelante. Los cuatro principios son: el prin-

\footnotetext{
${ }^{6}$ Esto significa ser pesados y balanceados unos contra otros, como concepciones de o concepciones sobre. Ello no solamente significa un peso y balance de dos o más concepciones sobre la libertad.

${ }^{7}$ Debo agradecer a Manuel Atienza por su comentario en este punto.
} 
cipio de la alternatividad, el principio de la densidad normativa, el principio de celeridad y el principio de coherencia.

\section{El principio de Alternatividad (PA)}

El PA requiere que una limitación externa de la libertad esté justificada como una alternativa a la defectuosa interacción social. El PA obviamente se parece a la libertad como principium en que él expresa la prioridad de la acción de los sujetos, es decir, la acción en una concepción de la libertad. Esta prioridad, nuevamente, no es absoluta. Es relativa en aquello que la interacción social pueda resultar un fracaso. Este fracaso, sin embargo, no puede suponerse, como Hobbes y Rousseau hicieron.

Lo que debe ser justificado es que una limitación externa del soberano es preferible a la ausencia de una limitación externa. La relación entre el soberano y los sujetos es de una naturaleza asimétrica. ${ }^{8}$ Esto implica la existencia de una brecha entre la demanda de legitimidad del soberano y la creencia de los sujetos en ello. Si la relación fuera simétrica, cualquiera de las demandas de legitimidad del soberano sería colmada, ipso facto, con la creencia de los sujetos en ello. Esto pone el argumento de vuelta en la senda del modelo de poder del contrato social, con su estela de legalismo fuerte.

El PA, como un principio de justificación, está basado en la capacidad de los sujetos de actuar dentro de concepciones de la libertad. Esto implica que las prácticas sociales son supuestas para ser autorreguladoras. Los sujetos involucrados en la interacción crean el significado. El significado que surge de la interacción social se refiere a las reglas que están arraigadas en una práctica social. Al mismo tiempo, estas reglas son constitutivas de estas prácticas.

La investigación científica, la interpretación musical, la carpintería, la educación, y la religión son todos tipos de prácticas. Cualquiera de estas prácticas tiene sus propias reglas por medio de las cuales estas prácticas son formas significativas de interacción. Mark Hunyadi ha argumentado convincentemente que la existencia de estas reglas sale a la superficie en el caso de un conflicto. ${ }^{9}$ Es decir, los conflictos revelan la existencia de reglas junto con las prácticas en las cuales surgen. Los conflictos, las reglas y el significado son condiciones necesarias para que exista una práctica. El espacio social puede ser considerado un entramado de una innumerable variedad de prácticas, implicando conflictos dentro de ellas y entre ellas.

Si cualquier conflicto puede ser prevenido a priori, enfrentamos una situación que es similar a la epistemologizada versión de la política de Hobbes. La definición del soberano del significado puede ser apta para prevenir

\footnotetext{
${ }^{8}$ P. Ricoeur, "Science et idéologie" en Du texte à l'action, Paris, Esprit Seuil, 1986, $310 \mathrm{p}$

${ }^{9}$ M. Hunyadi, La vertu du conflit. Pour une morale de la médiation, Paris, Cerf, 1995.
} 
o solucionar conflictos. Al mismo tiempo, sin embargo, pone en peligro la existencia de todas las prácticas sociales. Como consecuencia, el espacio social y político, o sociedad y Estado, serían idénticos.

El resultado de esto es que el sujeto, como un agente moral autónomo, es dejado de lado. Lo que le queda son esferas accidentales donde puede actuar en concepciones de la libertad mientras no son reguladas por el soberano. Este puede intervenir en cualquiera de ellos siempre que lo considere adecuado.

En el PA, el caso es el contrario. El soberano puede intervenir sólo a condición que se argumente que su limitación externa es preferible a una limitación interna de la libertad como una razón para la acción, debido a un fracaso de la interacción social.

\section{El principio de Densidad Normativa}

El principio de densidad normativa (PN) somete una limitación externa a la justificación en lo referido a la densidad del impacto normativo. Puesto brevemente, las sanciones necesitan una justificación especial porque ellas incluyen una doble restricción de la libertad. Primero, las limitaciones externas son concepciones sobre la libertad. Ellas excluyen la acción en una concepción de la libertad. Esta es una primera restricción. En segundo lugar, si están acompañadas por una sanción, el propósito, la meta, o el fin de la regla únicamente puede ser cumplido en la forma que es prescrito. Si el patrón de comportamiento no es cumplido en esta forma, se imputa una sanción. Esto previene al sujeto otra vez de actuar de acuerdo con concepciones de la libertad. ${ }^{10}$

Las limitaciones externas no son por sí mismas razones excluyentes de la acción. Si lo fueran, estamos nuevamente en el camino del modelo de poder. En el modelo de compensación, sin embargo, el sistema legal sólo tiene un modesto propósito general que es hacer posible la moral.

Si la compensación está justificada en el PA, no se sigue automáticamente que una sanción es la manera más preferible para conseguir el propósito, meta o fin de la limitación externa realizada.

Hart criticó convincentemente tanto el concepto austiniano y kelseniano de una norma jurídica. Acorde con él, cualquier sistema jurídico contiene reglas que confieren poderes. Las reglas pueden conferir poderes a funcionarios. Tales reglas asignan un poder a un funcionario para crear o cambiar una regla y para aplicarla. Al mismo tiempo, estas reglas hacen posible el

\footnotetext{
${ }^{10}$ Cuando una persona está en prisión, su capacidad para actuar de acuerdo con concepciones de la libertad es por definición limitada. Si tiene que pagar una multa, él no puede gastar el dinero de acuerdo con su propio deseo.
} 
reconocimiento de reglas, tanto por funcionarios y ciudadanos. Por lo general, las reglas que confieren poderes, no prescriben sanciones.

Aun las reglas pueden también conferir poder a personas privadas. En virtud de tales reglas, las personas privadas pueden otorgar testamentos, casarse o hacer contratos. Nuevamente estas reglas no son órdenes, mucho menos son respaldadas por amenazas o hay ahí una "conexión esencial" con una sanción. Nadie tiene una obligación, $p$. ej., de casarse. Si una persona quiere casarse, tiene que cumplir el patrón de comportamiento de lo que cuenta como un matrimonio válido. Si no lo hace, simplemente ahí no habrá matrimonio, aunque quizá haya otra forma de relación.

Mientras Hart consigue desconectar la validez de una limitación externa y una sanción, el PN requiere un paso más. Si no hay una conexión esencial o necesaria entre una regla y una sanción, la relación es contingente. En esta caracterización, la relación entre una regla y una sanción debe ser justificada.

La justificación de una sanción incluye un argumento del por qué es necesaria la limitación suplementaria de la libertad. Una sanción en términos pecuniarios o como una limitación física de la libertad es únicamente una opción entre una gran variedad de posibilidades para cumplir un patrón de comportamiento. La extensión de estas posibilidades tiene un grado variable de densidad normativa, con la sanción como el máximo. Ello incluye técnicas regulativas como información, incentivos como reducción de impuestos, autorregulaciones basadas en códigos de conducta o convenios, distinciones y similares.

El punto es que el castigo del comportamiento debe ser justificado porque la libertad como principium requiere que la acción en una concepción de libertad tenga prioridad sobre la acción en una concepción sobre la libertad. En el PA, éste debe pesar más que aquél. Como resultado, el tipo de concepción a ser realizado es una concepción sobre la libertad. La sustitución de una concepción sobre la libertad por una concepción de la libertad no puede, sin embargo, justificar automáticamente que ésta sea impuesta con una sanción. Lo que debe ser realizado es un fin, un propósito o una meta.

Luego, el PN requiere que los medios de realización del fin, propósito o meta de la regla resulten de un proceso de pesar y contrapesar las alternativas. Una alternativa para una regla que castiga la posesión y el uso de drogas podría ser una campaña de información en escuelas. Tal campaña informa acerca de las consecuencias negativas del uso de drogas. Esto puede ir junto con un convenio entre el gobierno y una escuela que tenga como objetivo conservar el establecimiento libre de drogas. Adicionalmente a ello, una distinción puede ser conferida a una escuela que adopte esta línea de conducta. Esta distinción puede ser complementada con una subvención adicional. Un 
premio puede ser concedido a una escuela que respete el convenio por un cierto período y así sucesivamente.

Para la realización de un fin, meta o propósito está disponible una variedad de posibilidades. Las sanciones son sólo una entre otras. Si la conexión esencial entre una regla y una sanción es rota, tiene que establecerse una conexión entre el fin, meta o propósito y los medios para realizarlos. El establecimiento de esta conexión es de lo que trata el PN.

Es innecesario añadir que los diferentes medios tienen una diferente densidad normativa. Su impacto en la libertad es distinto. Cae por su propio peso que debe ser preferido el instrumento con la menor densidad normativa comparado a las sanciones. Dicho de otra forma, si se usa una sanción, su justificación implica un mayor peso de las alternativas con un impacto normativo más débil.

\section{El principio de celeridad o temporalidad}

El principio de celeridad (PC) introduce la dimensión temporal en el sistema jurídico. En el legalismo fuerte, el sistema jurídico es un conjunto intemporal de reglas. Ellas representan la realidad y absorben el terreno del significado. En la visión de la legisprudencia sobre la materia, las reglas o limitaciones externas son un asunto de la creación humana. La creación de la regla está, como cualquier actividad humana, relacionada con condiciones históricas. Es decir, la actividad humana está repleta de temporalidad.

Las teorías que reclaman tener acceso directo a la realidad, como la de Hobbes o Rousseau, niegan el carácter temporal de este acceso. El conocimiento provisto por este tipo de teorías es ontológicamente verdadero. En el opuesto de estas teorías de la realidad, las teorías sobre la realidad consideran que este acceso debe ser mediado. Es decir, el acceso a la realidad es mediado por una teoría. Propongo llamar a este tipo de teoría una teoría analítica o "paradigma". Las teorías analíticas se basan, por su parte, en otra teoría analítica y así sucesivamente. Las teorías de la realidad niegan la mediación por una teoría analítica. A diferencia de las teorías sobre la realidad, ellas reclaman una verdad absoluta. Por su parte, estas teorías sobre la libertad únicamente reclaman un conocimiento objetivo o conocimiento incondicional. El conocimiento incondicional se refiere a una estructura teórica de la cual depende.

La dependencia teórica de una teoría puede ser aprehendida como la traslación epistemológica de la imperfección humana debido a la temporalidad de la condición humana. La conciencia de la naturaleza histórica del conocimiento no debería tornarse en escepticismo. Sólo induce a una forma de relativismo respecto de la verdad ontológica del conocimiento. 
Esta visión sobre la temporalidad corrobora la distinción entre la verdad y el significado. El significado está conectado con un contexto de participación. Lógicamente hablando, la verdad en el sentido filosófico no puede estarlo. Algo es verdadero o no lo es. Una proposición puede ser verdadera dado un cierto contexto. Sin embargo, esto es diferente de la pretensión de que una proposición es ontológicamente verdadera.

La acción moral y política no cualifica para la verdad ontológica. Este es el error básico de las teorías del contrato social. Ellas reclaman tener acceso directo a la realidad y así establecen la única estructura normativa para la organización del espacio político.

Lo que sirve para la explicación en el campo del conocimiento similarmente se aplica a la justificación en el terreno de la acción. ${ }^{11}$ Sobre esta pretensión, la verdad viene a justificar la creencia. Por razones de brevedad, no entraré a su justificación. Es suficiente decir que la justificación es una forma de acción. Si la verdad puede ser alcanzada, es mediada por una teoría. La teoría analítica que media en el acceso a la realidad al mismo tiempo bloquea el acceso directo a ella. La verdad es calificada como el "verdadero conocimiento" que es presupuesto por lo que propongo llamar "cognitivismo temporal".

La variedad de posibles concreciones del concepto de reglas de libertad descarta la opción de algún "verdadero significado" de la libertad. La opción por una concepción sobre la libertad es sometida a justificación. En el PA, esta justificación se centra en la justificación externa como una alternativa para la defectuosa interacción social. En el PA, esta densidad normativa de la justificación externa se debe justificar. A su turno, el PC enfatiza el carácter histórico general de cualquier justificación.

El PC limita la proposición normativa sometida a justificación en el PA y el PN desde la perspectiva del tiempo. Una limitación externa puede ser justificada por ambos de estos principios en un cierto momento de tiempo.

Al respecto, deben ser notados dos aspectos importantes del PC. Primero, debe ser mostrado que la limitación externa, aparte de su contenido que es limitado en el PA y el PN, viene en el "tiempo correcto". Circunstancias concretas hit et nunc pueden justificar una limitación externa.

En el opuesto de las circunstancias concretas, encontramos una realidad social ahistórica. Esta es la realidad social como es concebida a través del espejo del legalismo fuerte. El legalismo fuerte apunta a apagar el botón del tiempo. Por el contrario, el legalismo débil o la forma de legalismo que está detrás de la legisprudencia toma seriamente la dimensión temporal de la acción humana. La racionalidad de la legislación como la principal preocu-

\footnotetext{
${ }^{11}$ Esto no sugiere que la explicación no sea de un tipo justificativo.
} 
pación de la legisprudencia obliga al legislador a tomar en consideración circunstancias concretas. Estas circunstancias están repletas de temporalidad.

Como consecuencia de esto, lo que estaba una vez en el momento correcto puede, después de un lapso de tiempo, quedar fuera de lugar. Este es el segundo aspecto del PC. Esto muestra que lo que una vez fue justificado puede tornarse en injustificado. Luego, la justificación de las limitaciones externas es un proceso de justificación en curso. Este proceso de justificación debe incluir la conciencia de que las limitaciones externas deben mantenerse en la senda de las cambiantes circunstancias. La legislación obsoleta o limitaciones externas que son erosionadas por el desuso no son legitimadas más. Ellas deben ser retiradas, cambiadas o modificadas en visión del PA y del PN.

\section{El principio de coherencia: la teoría del nivel de coherencia}

El principio de coherencia (PCO) es un principio de justificación de limitaciones externas desde la perspectiva del sistema legal como un todo. Un sistema legal no es una cadena estática de limitaciones externas; al contrario, es un conjunto complejo y dinámico de proposiciones entrelazadas acerca de lo que debería ser hecho y cómo debería ser hecho.

En alguna pretensión un tanto fuerte, se podría decir que cualquier cambio en el sistema lo afecta como un todo. Complejo, como debe ser por su misma naturaleza, se vuelve cada vez más complicado. La complicación de un sistema jurídico es debido principalmente a su crecimiento exponencial. Resultante de esto, el carácter sistemático del sistema jurídico corre el riesgo de ponerse en peligro.

De ahí, la idea de coherencia en un sistema jurídico puede ser articulada. La coherencia es a menudo interconectada con la consistencia. La consistencia significa la ausencia de contradicciones dentro del conjunto de proposiciones que es llamado una teoría. Una contradicción hace el sistema inconsistente. En la idea que la consistencia es considerada una condición de la coherencia, una contradicción puede hacer el sistema también incoherente.

Aparte de esta relación entre la coherencia y la consistencia, unos podrán decir que la consistencia es un asunto de todo o nada. La coherencia, a su turno, es un asunto de grado. En esta visión, la consistencia es una necesidad lógica mientras que la coherencia se refiere a "tener sentido como un todo".

La relación entre coherencia y consistencia puede ser definida aún de una manera diferente. Si coherencia significa "tener sentido como un todo" consistencia puede ser tomado como una específica y fuerte manera de tener sentido. Entonces sólo parece como si la consistencia fuera un asunto de todo o nada, mientras la coherencia es un asunto de grado. 
Desde la perspectiva que estamos tratando aquí, la coherencia tiene que ver con el discurso o un conjunto de proposiciones. Estas proposiciones pueden tener coherencia en diferentes formas. La consistencia es una de ellas. Si ellas forman una unidad en una forma consistente, tenemos un todo lógico o consistente, es decir, un conjunto de proposiciones libre de contradicciones. En la consistencia, como una concepción de coherencia, existen otras maneras de tener sentido.

Estas aparecen cuado el "todo" es ampliado para incluir el contexto de participación. El derecho no es un conjunto de proposiciones "girando sobre sí mismo". Debe ponerse en contacto con la interacción social que regula. Cuando el todo es ampliado en ese sentido, la distinción entre consistencia y coherencia se hace más clara.

Con esto en mente, podemos proceder a la articulación del PCO. El PCO puede ser distinguido como una teoría distinta que propongo llamar la teoría del nivel de coherencia. En general, deben ser distinguidos cuatro niveles de coherencia.

\section{a. Coherencia ${ }_{0}$}

El primer nivel no es específico para la teoría. Es un nivel de coherencia por debajo del cual nada tiene sentido. Es llamado el nivel de coherencia ${ }_{0 .}$ Este nivel tiene que ver con el nivel elemental del habla (digamos, una sentencia, una decisión judicial o legislativa). Si allí aparece una contradicción en este nivel elemental del habla, los posteriores elementos del discurso estarían afectados por ésta. La coherencia ${ }_{0}$ es condición necesaria para que cualquier discurso tenga sentido. Esto requiere la ausencia de contradicciones en el elemental nivel del habla. Se le ha denominado acertadamente "consistencia simultánea". ${ }^{12}$

Además, la exigencia de coherencia ${ }_{0}$ no es universal en el sentido de ser una exigencia idéntica para cada y todo tipo de discurso. Ello depende de qué cuenta como un nivel elemental del habla. Este, a su turno, depende del contexto. En el discurso poético será menos limitado que en un discurso en sentido lógico. Todo tipo de discurso tiene, por así decirlo, un elemental nivel del habla. Aunque este nivel puede ser diferente dependiendo del tipo de discurso, la necesidad de coherencia ${ }_{0}$ por sí misma es una universal. De esta manera no es afectada por el tiempo.

${ }^{12}$ L. A. Kornhauser y L. G. Sager, "Unpacking the Court", 96 Yale Law Journal (1986), 82-117; P. Winch, "The Idea of Social Science and its Relation to Philosophy", London, Routledge, 1990 ( $2^{\mathrm{da}}$ ed), 61. 
b. El nivel de coherencia

La necesidad de coherencia cambia cuando es añadida la dimensión temporal. Cuando la dimensión temporal es tomada en consideración, el nivel de coherencia ${ }_{0}$ no es afectado. Cuando dos resoluciones judiciales en un caso similar son comparadas, ambas deben satisfacer la necesidad de coherencia . $_{\text {. }}$ Además, queremos que las decisiones sean similares porque los casos son similares. Si un juez condena a un ladrón a una multa de $100 €$, la justicia formal obliga a dictar la misma multa en un caso posterior y similar. Nuestro sentido de justicia puede ser conmocionado si éste no fuera el caso.

La justicia formal parece ser más similar a la consistencia. Hay principalmente dos razones para ello. La primera razón es el carácter reglado del derecho. El carácter reglado del derecho es fundado en el proceso de epistemologización de la filosofía. Este proceso dio lugar al desarrollo de las ciencias naturales. Para las ciencias naturales, la realidad es expresada en reglas. La gramática de la realidad es expresada en reglas matemáticas. Las verdades científicas son ecuaciones matemáticas. Al menos en algunas interpretaciones de la ciencia moderna, la realidad es, ontológicamente hablando, matemática. La imitación de las ciencias naturales por las ciencias del hombre resulta en el carácter reglado de éstas.

La segunda razón está relacionada con la primera. Las reglas legales, como reglas científicas, deben ser aplicadas igualmente a casos iguales. Si no lo fueran, el carácter reglado quedaría afectado. Sin embargo, a diferencia de las reglas lógicas, el carácter reglado de las limitaciones externas expresa un juicio de valor. El valor que es expresado por el carácter reglado del derecho es la igualdad. En la libertad como principium la libertad debe ser igual para todos. Se sigue de lo anterior que la necesidad de un tratamiento igual para casos iguales resulta de una demanda normativa. Esta demanda establece y corrobora el carácter reglado del derecho. Es porque cuidamos de la igualdad que es preferido el derecho como reglas al, por ejemplo, derecho como mandatos.

Entonces, la asimilación del derecho a las ciencias naturales acorde con el legalismo fuerte conducirá a exigencias idénticas en cuanto a la consistencia. La razón principal del por qué éste no es el caso es que la dimensión temporal es dejada fuera de vista. Esto significa que ninguna distinción se hace entre la coherencia ${ }_{0}$ y la coherencia . La coherencia $_{0}$, como uno recuerda, requiere la ausencia de contradicciones en la unidad elemental del habla de un discurso. La ausencia de distinción entre la coherencia ${ }_{0}$ y la coherencia ${ }_{1}$, por su parte, niega que unidades elementales del habla puedan ser identificadas. Toma la consistencia para ser un asunto de todo o nada. Como resultado, el todo es el que debe ser consistente para tener sentido del todo. 
Una vez que la dimensión temporal es introducida, afecta el proceso de aplicación de reglas. Se puede decir que es la dimensión del tiempo lo que hace diferente al derecho de las ciencias naturales. Si la aplicación de reglas es principalmente una operación lógica, la introducción de la dimensión temporal implica que los aspectos temporales de esta operación deben ser considerados. Estos aspectos temporales hacen que una justificación de decisiones sea sustituida por una mera aplicación de reglas. La justificación incluye que la identidad de casos es ajustada a sus similitudes. La conclusión de que dos casos son similares implica un juicio de valor que requiere justificación. Esta conclusión no es precisa; es a lo más convincente.

Puesto que la justificación es sometida a condiciones temporales, difícilmente puede esperarse que el conjunto de limitaciones externas que de ahí resulten sea lógicamente consistente. Al contrario, varía con el tiempo.

En lo que respecta a la toma de decisiones judiciales esto significa que puede partir de decisiones anteriores. La justicia formal como una regla de toma de decisiones no es absoluta, puesto que la toma de decisiones es sometida al tiempo. Partir de una regla o un precedente es posible a condición de que esté justificada, mientras que el siguiente precedente no necesita justificación.

Las cosas son similares, aunque ligeramente diferentes, desde la perspectiva del legislador. De hecho, la libertad de éste es mucho más amplia que la del juez. Los jueces están limitados por las reglas del respectivo sistema jurídico. Puesto que los legisladores crean y pueden cambiar estas reglas ellos no están, lógicamente hablando, limitados por cualquiera de ellas. Los aspectos de cambio y creación de limitaciones externas requieren dos diferentes conjuntos de observaciones. El primero relacionado con la coherencia ${ }_{1}$, mientras que el segundo trata de otro nivel de coherencia que será tratado en el siguiente subparágrafo.

Un juez no debe justificar el hecho de que siga la regla o el precedente. Lo único que tiene que justificar es partir de ellos. El legislador por su parte puede ser llamado a justificar ambos, el status quo y una partida de una situación existente en el PA, el PN y el PC. Paradójicamente, el deber de justificación del legislador en la visión del PCO es, en un sentido, más fuerte que la del juez.

El carácter específico del deber del legislador está relacionado con el hecho de que las limitaciones externas de la libertad están sometidas a justificación en el PA y el PN. Con tal de que la situación S no cambie, un cambio de la limitación externa implicaría una injusticia formal. Si todos los A han de ser tratados como los B en una existente limitación externa $\mathrm{R}$, 
cualquier cambio de $\mathrm{R}$ tiene como resultado un tratamiento diferente de $\mathrm{A}$ desde ese momento. Por lo tanto, se requiere una justificación. ${ }^{13}$

Si ninguna distinción fuera hecha entre la coherencia ${ }_{0}$ y la coherencia ${ }_{1}$, ningún cambio sería posible. Es decir, cualquier cambio sería excluido por la exigencia de justicia formal. El juez no tiene que justificar la adhesión al precedente aunque tiene que justificar el partir de él. El legislador, por su parte, tiene que justificar ambos, el status quo y el cambio de las limitaciones externas. Esto es, brevemente, lo que requiere el nivel de coherencia ${ }_{1}$ desde la perspectiva de la legisprudencia.

Cuando nos concentramos en el cambio de las limitaciones externas desde la perspectiva del juez, tiene que ser hecha una distinción adicional que abra el camino para un diferente nivel de coherencia.

\section{c. El nivel de coherencia}

Un juez que se aparta del precedente viola las exigencias de la justicia formal Esta violación puede ser compensada por la justificación. La visión expuesta hasta ahora necesita alguna reserva. Presupone la idea que las reglas están "justo ahí" y ellas saltan del reglamento directamente al escritorio del juez. La realidad es, sin embargo, más compleja. Los jueces deben elegir la regla que aplican a un caso. Un ejemplo de manual es si un contrato de arrendamiento es regulado por un régimen contractual o por un régimen de propiedad. Tiene que ser escogido el conjunto específico de reglas. Esta elección no es precisa. Las consecuencias de ambos regímenes contienen serias diferencias en cuanto a los derechos y obligaciones del propietario y arrendatario. En la coherencia ${ }_{1}$, se tiene que seguir la línea de decisión por uno de estos regímenes. Partir de ella es posible si está justificada. Para esta justificación, se necesita un nivel suplementario de coherencia.

Este nivel de coherencia, es decir, el nivel de coherencia ${ }_{2}$, proporciona argumentos para partir de las exigencias de la coherencia ${ }_{1}{ }^{14}$

${ }^{13}$ Si una medida tributaria es justificada en el PA y en el PN en orden a incrementar la actividad económica, puede ser que los efectos de $\mathrm{R}$ sean insuficientes para realizar la meta. Por consiguiente, R deberá ser cambiado. Este cambio es sometido a justificación. Si S cambia con el tiempo, esto puede ser una razón para cambiar R. Al contrario, ello puede ser también una razón para no hacerlo. En la primera hipótesis, es requerida una justificación en el PN y el PA. En la segunda, debe ser dada una razón para no cambiar R. Puede resultar, en efecto, que la medida tributaria alcanzó su meta. Si la producción económica ha alcanzado el nivel, la medida que pretende realizar la medida tributaria se torna en injustificada.

${ }^{14} \mathrm{El}$ potencial del nivel de coherencia ${ }_{2}$ puede ser ilustrado con un ejemplo de la toma de decisiones judiciales de la corte laboral en Antwerp (Arbeidsrechtbank Antwerpen, Junio 26, 1979, Rechtskundig Weekblad, 1979-80, 1058). Según el Real Decreto del 4 de noviembre de 1963, una esposa que permanece en casa cuidando a sus hijos cualifica para la (sic) "prima para la esposa en el hogar". En 1979 un esposo reclama la prima. En contra del claro significado del 
De lo anterior se sigue que apartarse de una línea de precedente está permitido si está justificado. Los argumentos que justifican tal salida son de un nivel diferente que la coherencia ${ }_{1}$. Ellos pertenecen al nivel de coherencia ${ }_{2}$. La interpretación sistemática es un caso ejemplar de argumentación en el nivel de coherencia ${ }_{2}$ desde la perspectiva del juez. En este nivel, todo el sistema jurídico es tomado en cuenta. Incluso, observaciones similares pueden ser hechas para otros métodos de interpretación.

Aparte de las exigencias de la coherencia ${ }_{1}$, la actividad legislativa es también sometida a las limitaciones del nivel de coherencia ${ }_{2}$. Como es el caso con el juez, los argumentos de la coherencia ${ }_{2}$ desde la perspectiva del legislador requieren que tome en consideración al sistema como un todo. En los argumentos de la coherencia ${ }_{2}$, el juez puede confiar en el carácter sistemático del sistema jurídico. La correspondiente perspectiva del legislador viene de la exigencia para constituir el sistema jurídico como un todo. ${ }^{15}$

texto de la ley, el juez decide por el demandante. Su argumento implicaba una referencia a otras reglas del sistema que proclamaban la igualdad del marido y la esposa. El acta matrimonial de 1976, la Convención Europea en Derechos Humanos de 1950 (ratificada por Bélgica por el estatuto del 13 de mayo de 1955, Mon. B., 19 de agosto de 1955), la Declaración Universal de Derechos Humanos de 1948, así como la doctrina jurídica sostienen esta posición. La decisión fue inconsistente con la precedente línea de la jurisdicción. A pesar de la violación de las exigencias de la coherencia ${ }_{1}$, esta decisión fue sostenida para tener más sentido como un todo. Desde ahora, ello fue más coherente que las decisiones anteriores. La decisión dependió de una interpretación sistemática de la regla de 1963. Una interpretación sistemática viene a leer una regla a la luz de otras reglas del sistema.

${ }^{15}$ Un ejemplo ilustrará esta posición. En la regla R1 las personas desempleadas recibirán un beneficio de desempleo U según un criterio fijo de distribución. Algún tiempo después, el soberano expide R2. En la regla R2, las empresas que empleen a personas calificadas para el beneficio de desempleo bajo R1, a su vez, cualifican para un premio que alienta el empleo de los económicamente inactivos. Ambos premios son pagados por el Estado. Una persona $\mathrm{P}_{2}$ que, al hacerlo, cualifica para el premio en $\mathrm{R} 2$ ofrece un trabajo a una persona P1 cualifica bajo $\mathrm{R}_{1}$ para el beneficio de desempleo. Ambos, $\mathrm{P}_{1}$ y $\mathrm{P}_{2}$, pueden haber pensado en tener un interés en que $\mathrm{P}_{1}$ obtenga un trabajo y un salario $\mathrm{S}$ y $\mathrm{P}_{2}$ obtenga el premio. Sin embargo, si el salario $\mathrm{S}$ de $\mathrm{P}_{1}$ excede sólo levemente su beneficio $\mathrm{U}$, él puede tener derecho a pensar que se le paga muy poco por su trabajo. Él puede pensar que lo que "realmente" gana por trabajar viene de [S - U]. Cuanto más pequeño sea el resultado de [S - U], estará más animado a pensar en ese sentido. Este problema es conocido como la trampa del desempleo. Los efectos simultáneos de $\mathrm{R}_{1}$ y $\mathrm{R}_{2}$ no se contradicen. Ellos simplemente anulan en gran medida los efectos del otro. Si ambos, $\mathrm{R}_{1}$ y $\mathrm{R}_{2}$, son reglas válidas y ex hypothesi, satisfacen las exigencias de la coherencia ${ }_{0}$ y están justificados en la coherencia ${ }_{1}$, sin embargo, ellos no necesariamente satisfacen las exigencias de la coherencia ${ }_{2}$. Su combinación afecta al carácter sistemático del sistema jurídico. Su existencia simultánea causa muchos problemas, incluyendo molestias administrativas, eventualmente procedimientos en la corte y similares, para un efecto que es cercano a cero. $\mathrm{R}_{1}$ y $\mathrm{R}_{2}$, puede ser dicho, no son eficaces. Entonces $R_{2}$ necesita una justificación suplementaria en el PCO a fin de mostrar que encaja con el sistema como un todo. Es decir, la coherencia ${ }_{2}$ desde la perspectiva del legislador, le requiere a tomar en consideración el carácter sistemático del sistema como un todo. Inclusive, evitando violaciones a la coherencia ${ }_{0}$ y a la coherencia ${ }_{1}$, puede violar la cohe- 
Cuando el juez argumenta en el nivel de coherencia ${ }_{2}$-por ejemplo, en interpretación sistemática- asume la unidad del sistema jurídico al tomarlo como un todo. La argumentación de la coherencia ${ }_{2}$ desde la perspectiva del legislador requiere que éste constituya esta unidad.

A diferencia del legalismo fuerte, la racionalidad del legislador no se presume de modo irrefutable. Si lo fuera, el modelo de compensación sería nuevamente sustituido por el modelo de poder. Es decir, el legislador tiene que justificar sus limitaciones externas de modo que ellas permitan al juez hacer argumentos de la coherencia ${ }_{2}$ de alguna manera.

Una vez que la posición central del juez es determinada, el lugar del legislador se hace más evidente. El activismo legislativo incluye una justificación activa de las limitaciones externas. A diferencia del juez, el legislador no puede asumir el carácter sistemático del sistema jurídico.

Las mayores limitaciones externas, aparte de sus aspectos de coherencia ${ }_{0}$ y coherencia ${ }_{1}$, para encajar el sistema como un todo se muestran cuando son vistas en el interior del sistema, es decir, ellas satisfacen la mejor justificación de la coherencia ${ }_{2}$. El supuesto de racionalidad del legislador, típicamente, pertenece a las premisas de legalismo fuerte puesto que, en éste, las limitaciones externas son consideradas representaciones de la realidad. En el legalismo fuerte, la creación de reglas o limitaciones externas son consideradas una reproducción de la realidad; en el legalismo débil, la construcción de reglas es sólo una construcción de reglas y no una reconstrucción de la realidad.

En esta reinterpretación de la premisa de racionalidad del legislador, no se presume que él deba ser racional. Su racionalidad debe seguirse de sus actos. Si esta presunción es parte de las premisas del legalismo fuerte, en el legalismo débil, sin embargo, la racionalidad del legislador es un asunto de justificación, no de presunción.

d. El nivel de coherencia

En el legalismo fuerte, los jueces aplican las reglas que crean los legisladores. La aplicación de reglas es un asunto teórico como lo es en las matemáticas. La creación de reglas, por su parte, es considerada un asunto político que no aparece en la pantalla de la teoría jurídica.

En el legalismo débil, sin embargo, tanto el juez y el legislador crean reglas y siguen reglas. El juez sigue reglas en la aplicación de reglas. Al mismo tiempo, él crea reglas individuales. El legislador, por su parte, sigue reglas mientras crea reglas generales o limitaciones externas. Las diferencias entre estas posiciones pueden ser considerables; ellas, sin embargo, no son opuestas. 
Por lo que se refiere a la posición del juez, las reglas no son auto-interpretables. El proceso de determinación de significado así como la elección de la regla necesita una teoría para ser racional. La racionalidad en la toma de decisiones, sin embargo, no es limitada para encajar en las nuevas decisiones dentro de un conjunto de reglas existentes. Esta es solamente una manera de presentar el asunto que puede ser catalogado como "racionalidad interna". Así, desde esta perspectiva puede decirse que las reglas existentes son racionales, coherentes o con sentido.

Sin embargo, en la articulación de la coherencia como "tener sentido como un todo" uno necesita otra perspectiva. No puede verse algo como un todo a menos que se incluya una perspectiva externa. Mientras el sistema jurídico como un conjunto de limitaciones externas puede ser internamente racional o coherente, el que tenga sentido como un todo requiere una perspectiva que permita verlo como un todo. Esto sólo es posible apoyándose sobre los bordes de lo que es considerado el todo. Además, diciendo que el todo se vuelve más coherente transformando algunos de sus elementos, el término comparativo necesita que el todo qua todo sea tomado en consideración. Esto nuevamente requiere una perspectiva externa que propongo llamar "racionalidad externa". Mientras que los niveles de coherencia ${ }_{1} \mathrm{y}$ coherencia ${ }_{2}$ se refieren a la racionalidad interna, su funcionamiento es condicionado por la racionalidad externa. Esta relación puede ser articulada de la siguiente forma.

La premisa básica del argumento es que las cosas no tienen significado propio. El significado es expresado a partir de algo. En esta objeción contra la doctrina del significado claro, se sigue que el significado de una regla es posterior a la interpretación, puesto que las reglas no hablan de sí mismas. Desde esta perspectiva, el seguimiento de la regla por el juez y el seguimiento de la regla por el legislador están en una posición similar.

El significado de las reglas no proviene de las reglas por sí mismas. El significado no puede ser comprendido simplemente mirándolas fijamente. ${ }^{16}$ La interpretación y el significado que resulta de ella es una construcción teórica que depende por sí misma de una teoría. La doctrina del significado claro como una aliada del legalismo fuerte niega esta dependencia teórica. El legalismo fuerte, como uno recuerda, se remonta a un acceso directo a la realidad; el legalismo débil, por su parte, confía sólo en un acceso indirecto a ella. Este acceso indirecto significa que una teoría es sobre la realidad y que su acceso a ella es mediado por un marco teórico. Este marco teórico es la teoría analítica de un sistema jurídico antes referida. 
Para que el sistema jurídico tenga sentido como un todo, los funcionarios legales que lo operan deben vigilar lo que lo hace un todo; que es un marco teórico del que depende el sistema jurídico. ${ }^{17}$ Esta dependencia teórica del sistema jurídico es de lo que trata el nivel de coherencia ${ }_{3}$.

El nivel de coherencia ${ }_{3}$ se articula mejor a través de la distinción entre el punto de vista interno y el externo que puede ser adoptado respecto a una regla. Mientras el punto de vista externo expresa las regularidades del comportamiento que puede ser conectado al comportamiento de seguir la regla, el punto de vista interno expresa el carácter normativo de la regla. La calificación de MacCormick de esta idea original de H.L.A. Hart viene a decir que el especialista jurídico, mientras adopta una perspectiva externa, incluye al mismo tiempo en su descripción el punto de vista interno. En esta posición, la erudición jurídica otorga todo el peso a las reglas como razones para la acción.

La calificación de MacCormick del punto de vista externo moderado de Hart, que acertadamente cataloga como el "punto de vista hermenéutico" refiere a una dinámica específica. Es una perspectiva que comienza desde el punto de vista externo hacia el punto de vista interno. La conexión entre el método propio del especialista -economía, moral, historia, sociología, derecho comparado, etc.- y el objeto "derecho" es probable que resulte, todos juntos, en un diferente entendimiento del objeto.

Aún en mi posición del asunto, la dinámica de la perspectiva hermenéutica de MacCormick puede ser revertida. Dicho duramente, un especialista que revela una lectura alternativa de un conjunto de reglas legales acorde con sus propios métodos adopta una posición "como si". Sus doctas conclusiones, puede decirse entonces, no tienen la misma autoridad que una decisión judicial. Incluso, en lo que respecta a que su lectura incluya el punto de vista interno del juez, sus conclusiones pueden estar muy cercanas a la manera como el juez lee la ley. Éste, tomando conocimiento del trabajo del especialista, aprecia una imagen virtual de sí mismo.

Esta imagen es virtual mientras el juez no adopte esta posición. El derecho y las investigaciones económicas ilustran este punto. Desde un punto de vista externo, el derecho y los especialistas económicos pueden revelar una nueva lectura de la regla de agravios.

Un ejemplo de manual es la investigación de Calabresi y Melahmed que elocuentemente revela una diferente visión de la dogmática de agravios. Aparte del significado de la regla de agravios considerada desde dentro del

${ }^{16}$ C. Perelman, "Avoir un sens et donner un sens" en Le champ de l'argumentation, Bruselas, Presses univ. Bruxelles, 1970, 64-78. 
sistema jurídico, un análisis económico informa acerca un significado alternativo desde una perspectiva externa. Cuando esta perspectiva externa es una moderadamente externa, o como la llama MacCormick, una perspectiva "hermenéutica", se obtiene el efecto reflejo. Un juez que retiene el nuevo significado invierte la dinámica del punto de vista hermenéutico. Es decir que desde un punto de vista interno que expresa la regla que es una norma para él, va hacia el punto de vista externo

Puede parecer como si el tercer nivel de coherencia es algún nivel suplementario que sólo es relevante cuando las reglas a ser aplicadas necesitan alguna interpretación. Dicho de otra forma, sólo si las reglas son confusas deben ser interpretadas. A fin de determinar su significado, el juez deberá entonces apoyarse sobre el borde del sistema como un conjunto de reglas. Ahí él encuentra herramientas suplementarias para interpretar esas reglas.

Esta posición es, sin embargo, errónea. La claridad de una regla no precede la interpretación por lo que sólo las reglas confusas deben ser interpretadas. Si las reglas fueran tenidas como claras por sí mismas, el significado puede existir en sí mismo o "ahí fuera", lo cual es un claro sinsentido. Al contrario, la claridad de una regla es el resultado de una interpretación que puede ser ocultada.

Una teoría de la interpretación con la ayuda de qué reglas son interpretadas no es en sí misma derecho. Ello no pertenece al sistema jurídico que consiste en un conjunto de reglas; aunque ello es necesario para un sistema jurídico para disponer como tal de una teoría.

Resumiendo, el comportamiento de seguir reglas incluye un aspecto cognitivo y volitivo. El aspecto volitivo del punto de vista interno, sin embargo, no es un puro acto de voluntad. Es, por así decirlo, completado con teoría que no está contenida dentro de la regla. Está contenida en la teoría analítica del sistema jurídico diciendo por qué las reglas son preferibles a los mandatos, y así por qué la libertad e igualdad son preferibles a la arbitrariedad, y por qué, por lo tanto, es preferible que los poderes en el espacio político estén separados, etc. Desde esa perspectiva, la teoría analítica del sistema jurídico orienta la elección de teorías aceptables de interpretación, es decir, las teorías para determinar el significado de las reglas del sistema jurídico resultan en el sistema jurídico teniendo sentido como un todo. En resumen, la teoría analítica del sistema jurídico es lo que hace del sistema jurídico un orden jurídico.

En la tesis de que el legislador, como el juez, es un seguidor de reglas, una explicación similar puede ser dada de su actividad. Como las reglas del sistema jurídico no son auto-interpretables, las reglas de la Constitución raramente contienen una indicación positiva en cuanto a la sustancia de las reglas jurídicas expedidas por el legislador. Su regla de comportamiento es entonces 
limitada a no violar las reglas que, se supone, que sigue. El seguimiento de reglas, sin embargo, incluye más que el deber minimalista de no violarlas. ${ }^{18}$

Si el seguimiento de reglas por el legislador implica como un mínimo o negativamente que ellas no sean violadas, ello incluye positivamente, sin embargo, o como un asunto de aspiración, que los derechos y deberes que incluye pueden ser efectivamente ejercidos, que ellos son suficientemente protegidos y hechos cumplir, respectivamente, etc. La aspiración del legislador es más que un asunto que merece un premio cuando es efectuado. Ello se parece más a un deber de aspirar a las mejores reglas posibles que a una simple aspiración política de hacerlo. Es con esta condición que el sistema legal empieza a tener sentido como un todo desde el punto de vista de la legisprudencia.

Ello podría ser empleado para decir justo en este punto que las "mejores reglas posibles" son un asunto de política, y esa política es un asunto de desacuerdo. Aquí vienen, sin embargo, los principios de la legisprudencia, con el PCO a la cabeza. Las circunstancias de la política hacen que ahí exista desacuerdo entre personas mientras que, al mismo tiempo, hay ahí una necesidad de actuar conjuntamente, al menos en ciertos campos. ${ }^{19}$ La política no se dirige al desacuerdo para evaporarlo; debe hacerlo viable.

Algunos dirán que esto se consigue en lo que respecta a los derechos humanos. Esto es correcto, y es además correcto decir que los derechos humanos son parte de la teoría analítica del sistema jurídico. El respeto por los derechos humanos se consigue con su no violación. La libertad individual es protegida por los derechos humanos como la exigencia de respeto para la libertad individual.

Esto es, sin embargo, sólo una manera de tener sentido de libertad. Ello es una estipulación negativa que proviene de la teoría analítica del sistema jurídico haciéndolo un orden jurídico. Sin embargo, el carácter reflexivo de la libertad requiere más que una protección negativa de algunas características esenciales de la libertad. Desde esta perspectiva, las reglas legales o las limitaciones externas de la libertad son sometidas a justificación en el principio de alternatividad, el principio de celeridad y el principio de densidad normativa. Esta justificación llega a una implementación positiva de la autonomía moral del sujeto. La justificación suplementaria en el principio de coherencia sostiene la conexión entre el concepto de libertad como parte de la teoría analítica del sistema jurídico y las reglas del sistema.

(trad. de Félix Morales Luna)

17 Junto con esto quisiera sostener que el sistema jurídico es en sí mismo una teoría. Lamentablemente, dadas las limitaciones de espacio, esta afirmación debe mantener su formulación dogmática. 